\title{
ANALISIS PENGARUH APLIKASI PEMBELAJARAN AKSARA SUNDA TERHADAP PEMAHAMAN SISWA DENGAN METODE TECHNOLOGY ACCEPTANCE MODEL
}

\author{
Haerul Fatah \\ Sistem Informasi, Teknologi Informasi, Universitas Bina Sarana Informatika, \\ Jl.Tanuwijaya No.4, Empang Sari, Tawang, Tasikmalaya \\ Email: haerul.hef@bsi.ac.id
}

(Diterima: 5 September 2019, direvisi: 12 Januari 2020, disetujui: 15 Januari 2020)

\begin{abstract}
Along with the times and the lack of cultural preservation, traditional culture is starting to be displaced by western culture. For example, Sundanese script culture, many people, especially Sundanese who do not know about Sundanese script, which is one of Indonesia's cultural heritage. To safeguard and preserve the culture of a Sundanese script in modern times, it is needed away and learning media that is appropriate to the current era. This research aimed to find out how much influence the Androidbased Sundanese alphabet learning application program has on Sundanese script student's understanding of high school students. This research used the Technology Acceptance Model method. The sample in this study were high school students at Senior High School 1, Singaparna. This study used a purposive sampling method. The results of this study indicated that the Android-based Sundanese alphabet learning application program has a positive influence on the understanding of Sundanese script learning in Singapore High School 1 Singapore.
\end{abstract}

Keywords: Sundanese script, Android, Technology Acceptance Model

\begin{abstract}
ABSTRAK
Seiring perkembangan zaman dan kurangnya pemeliharaan budaya, saat ini budaya tradisional mulai tergeser oleh budaya barat, contohnya budaya aksara sunda, banyak masyarakat terutama suku Sunda yang tidak mengetahui tentang aksara sunda, yang merupakan salah satu warisan budaya Indonesia. Untuk menjaga dan memelihara budaya aksara Sunda di zaman modern, maka diperlukan cara dan media pembelajaran yang sesuai dengan zaman saat ini. Penelitian ini bertujuan untuk mengetahui seberapa besar pengaruh program aplikasi pembelajaran aksara sunda berbasis android terhadap pemahaman pelajaran aksara sunda pada siswa-siswi Sekolah Menengah Atas. Penelitian ini menggunakan metode Technology Acceptance Model. Sample pada penelitian ini adalah siswa-siswi Sekolah menengah Atas Negeri 1 Singaparna. Pengambilan sample dalam penelitian ini menggunakan metode purposive sampling. Hasil penelitian ini menunjukan bahwa program aplikasi pembelajaran aksara sunda berbasis android memberikan pengaruh positif terhadap pemahaman pelajaran aksara sunda pada siswa-siswi Sekolah menengah Atas Negeri 1 Singaparna.
\end{abstract}

Kata Kunci : Aksara Sunda, Android, Technology Acceptance Model

\section{PENDAHULUAN}

Aksara sunda merupakan huruf yang berasal dari tanah sunda, merupakan huruf yang digunakan pada zaman dahulu kala. Aksara sunda terbagi menjadi dua, yaitu aksara sunda baku dan aksara sunda kuno. Aksara sunda baku merupakan aksara yang sudah di sesuaikan, berdasarkan aksara sunda kuno. Seiring dengan perkembangan jaman dan kurangnya pemeliharaan budaya banyak diantara kita terutama suku Sunda yang tidak mengenal bahkan tidak tahu aksara sunda [1].

Aksara Sunda adalah salah satu unsur budaya yang harus dilestarikan khususnya oleh masyarakat Jawa Barat, karena aksara Sunda merupakan aksara tradisi hasil karya ortografi masyarakat Sunda melalui perjalanannya sejak abad lalu hingga saat ini. Untuk meningkatkan usaha pemeliharaan dan 
pemberdayaan aksara Sunda khas di Jawa Barat maka tepat kiranya jika dibuat alat informasi interaktif untuk memperkenalkan aksara Sunda kepada seluruh masyarakat[2].

Kehadiran globalisasi tentunya membawa pengaruh bagi kehidupan suatu negara termasuk Indonesia. Pengaruh tersebut meliputi dua sisi yaitu pengaruh positif dan pengaruh negatif. Pengaruh globalisasi di berbagai bidang kehidupan seperti kehidupan politik, ekonomi, ideologi, sosial budaya dan lain-lain. Tanpa disadari, globalisasi dapat menggeser nilai-nilai budaya yang ada di Indonesia dan mengganti dengan budaya barat. Khususnya dikalangan anak muda yang cenderung lebih tertarik dengan budaya barat dibandingkan dengan budaya kita sendiri. Jika terus dibiarkan bukan tidak mungkin budaya asli kita akan musnah karena anak muda selaku generasi bangsa tidak mengenal dan bahkan mulai melupakan budaya asli mereka. Contohnya aksara Sunda, banyak anak muda khusunya para pemuda asli jawa barat yang tidak tahu bahkan tidak mengenal aksara Sunda.

Untuk meningkatkan usaha pemeliharaan dan pemberdayaan aksara Sunda, maka tepat kiranya jika menggunakan program aplikasi pembelajaran aksara Sunda berupa animasi interaktif dan game yang tentu akan sangat berperan penting untuk mensosialisasikan aksara Sunda, karena dengan animasi interaktif, masyarakat akan lebih tertarik dan lebih mudah memahami dalam penulisan aksara Sunda.

"Game tidak hanya dimanfaatkan untuk hiburan saja, tetapi juga sebagai media edukasi. Manusia memiliki sifat dasar lebih cepat mempelajari segala sesuatu secara visual-verbal, sehingga game juga baik jika dilibatkan dalam proses pendidikan"'[3].

Perkembangan teknologi informasi dan komunikasi membawa dampak besar pada berbagai bidang kehidupan, salah satunya yaitu bidang pendidikan harus memikirkan dan melaksanakan pembelajaran yang sesuai dengan kebutuhan siswa dan mengemas proses pembelajaran yang lebih bermakna, menarik, mengikuti perkembangan iptek, serta dapat membantu siswa meningkatkan prestasi belajarnya[4].

Tujuan dari penelitian yang dilakukan adalah untuk mengetahui seberapa besar pengaruh program aplikasi pembelajaran aksara sunda berbasis android terhadap pemahaman pelajaran aksara sunda pada siswa-siswi Sekolah Menengah Atas. Penelitian ini menggunakan metode Technology Acceptance Model. Sample pada penelitian ini adalah siswa-siswi Sekolah menengah Atas Negeri 1 Singaparna.

\section{TINJAUAN PUSTAKA}

Dwi Suhartini dan Wiwik Handayani dalam penelitiannya menganalisis perilaku dosen dalam penerimaan teknologi informasi (Acceptance) dalam menunjang tugas dosen dengan didasarkan pada dua keyakinan yaitu Perceived Usefulness (PU ) dan Perceived Ease of Use (PEOU). Populasi penelitiannya adalah dosen pada perguruan tinggi di Surabaya. Subyek penelitian adalah dosen yang telah menggunakan teknologi informasi. Jumlah sampel sebanyak 300 responden. Teknik pengambilan sampel purposive sampling dengan teknik analisis SEM. Hasilnya, hipotesis diterima adalah (H1) Perceived Ease of Use (PEOU) berpengaruh positip terhadap penerimaan teknologi informasi, $(\mathrm{H} 2)$ Perceived Ease of Use (PEOU) berpengaruh secara positif terhadap Perceived Usefulness (PU) sedangkan hipotesis ditolak adalah (H3) Perceived Usefulness (PU) berpengaruh secara positif terhadap Acceptance (Acc) dan (H4) Perceived Ease of Use (PEOU) berpengaruh secara positif terhadap Acceptance (Acc) dengan dimediasi oleh Perceived Usefulness (PU)[5].

Dalam peneilitiannya, Dwi Yuniarto menggunakan metode Technology Acceptance Model (TAM) untuk mengetahui penerimaan para Dosen mengenai kebijakan Kopertis Wilayah IV Jawa Barat dan Banten yang mulai menerapkan aplikasi laporan Beban Kerja Dosen dan evaluasi pelaksanaan Tridharma Perguruan Tinggi secara online. Pada Penelitiannya menggunakan populasi sebanyak 237 Dosen Tetap yang aktif pada tahun akademik ganjil 2017/2018 berdasarkan data dari forlap.ristekdikti.go.id. Dari populasi tersebut diperoleh sampel sebanyak 147 Dosen Tetap dengan menggunakan metode Kriejcie dan Morgan. Hasil penelitian tersebut menunjukan bahwa variabel di dalam model TAM yaitu perceived usefulness dan perceived easy of use berpengaruh positif baik secara masing-masing maupun bersamaan terhadap penggunaannya[6].

Penelitian yang dilakukan oleh Fuad Budiman dan Fefri Indra Arza dengan judul "Pendekatan Technology Accepted Model (TAM) dalam Kesuksesan Implementasi Sistem Informasi Manajemen Daerah". Hasil penelitian menyimpulkan bahwa persepsi kemudahan penggunaan aplikasi SIMDA 
berpengaruh signifikan positif terhadap persepsi kemanfaatan dan sikap penggunaan, Persepsi kemanfaatan aplikasi SIMDA berpengaruh signifikan positif terhadap sikap penggunaan dan perilaku pengguna, dan persepsi sikap penggunaan aplikasi SIMDA berpengaruh signifikan positif terhadap perilaku pengguna[7].

Ediraras dan Yananto (2008) telah melakukan penelitian tentang implikasi dan penerapan TIK pada UMKM yang berpartisipasi dalam UG-ICTA pada tahun 2008 dengan menggunakan pendekatan TAM dan menggunakan data primer dengan variabel persepsi pengguna terhadap kemudahan penggunaan TIK-PEOU, persepsi pengguna terhadap manfaat TIK-PU dan penerimaan pengguna terhadap TIK-PU. Variabel lain yang ditambahkan adalah pemanfaatan TIK terhadap penentuan strategi usaha (Strategy Execution), potensi persaingan usaha (Competitive Potential) dan tingkat pelayanan (Service Level). Sedangkan variabel dari luar (external variables), seperti karakteristik pengguna (user characteristics) yang meliputi bidang usaha, besarnya omzet penjualan dan lama waktu adopsi (time of system adoption) tidak diteliti karena kontribusinya dalam TAM dianggap tidak signifikan, sehingga dapat diabaikan meskipun mempunyai pengaruh secara tidak langsung terhadap penerimaan teknologi [8].

Penelitian yang dilakukan oleh Arie Muhammad dan Totok Dewayanto dengan judul "Analisis Penerimaan Komputer Mikro dengan Menggunakan Technology Accepted Model (TAM) Pada Kantor Akuntan Publik (KAP) Di Jawa Tengah". Hasil penelitiannya menyimpulkan bahwa kemudahan penggunaan komputer mikro akan mengurangi usaha (baik waktu maupun tenaga) seseorang (auditor) di dalam melaksanakan aktivitas audit. Perbandingan kemudahan tersebut memberikan indikasi bahwa seseorang (auditor) yang menggunakankomputer mikro bekerja lebih mudah dibandingkan dengan orang yang bekerja tanpa menggunakan komputer mikro. komputer mikro juga dipercaya lebih fleksibel, mudah dipahami, dan mudah pengoperasiannya sehingga mempengaruhi auditor untuk mengetahui betapa pentingnya penggunaan komputer mikro dan hal tersebut akan mendorong auditor untuk menerima penggunaan komputer mikro[9].

\section{Hipotesis}

Penelitian ini fokus pada tiga variabel utama yaitu kemudahaan penggunaan, isi materi dari aplikasi dan manfaat aplikasi terhadap pemahaman pembelajaran aksara sunda. Dengan demikian hipotesis penelitian ini adalah sebagai berikut:

H1: Kemudahan penggunaan program aplikasi pembelajaran aksara sunda berbasis android berpengaruh positif terhadap pemahaman pelajaran aksara sunda.

$\mathrm{H} 2$ : Isi materi dari program aplikasi pembelajaran aksara sunda berbasis android berpengaruh positif terhadap pemahaman pelajaran aksara sunda.

H3: Manfaat dari program aplikasi pembelajaran aksara sunda berbasis android berpengaruh positif terhadap pemahaman pelajaran aksara sunda.

\section{METODE PENELITIAN}

Metode yang digunakan pada penelitian ini adalah pendekatan Technology Acceptance Model (TAM). Untuk mengetahui pengaruh teknologi diterima dengan baik/tidak atau berdampak positif/negatif dipengaruhi oleh kemudahan penggunaan dari teknologi, isi materi dari aplikasi dan manfaat dari teknologi tersebut.

\section{Teknik Pengumpulan Data}

Pengumpulan data dalam penelitian ini dilakukan dengan metode survey, yaitu dengan cara menyebarkan secara langsung daftar pertanyaan berupa kuesioner kepada responden. Dalam penelitian ini yang dijadikan sampel adalah siswa-siswi SMAN 1 Singaparna dengan jumlah responden sebanyak 100 siswa. Metode survey melalui kuesioner ini menghasilkan data primer yang merupakan acuan bagi peneliti dalam mengelola data untuk pengujian hipotesis.

\section{Metode Analisa Data}

Dalam penelitian ini, analisis kuantitatif dilakukan dengan analisis regresi linier berganda. Hal ini dilakukan karena analisis regresi linier berganda digunakan untuk mengetahui pengaruh atau hubungan secara linier antara dua atau lebih variabel independen dengan satu dependen [10]. 
Sebelum dilakukan analisis data menggunakan rumus regresi linier berganda, terlebih dahulu dilakukan uji validitas dan uji reliabilitas pada instrument penelitian, uji validitas dilakukan untuk mengetahui akurasi kelayakan instrument yang akan diukur, sedangkan uji reliabilitas dilakukan untuk menguji tingkat ketepatan instrumen akurat atau tidak, selanjutnya dilakukan uji asumsi klasik. Uji asumsi klasik digunakan untuk mengetahui ada tidaknya normalitas residual, multikolinieritas, dan heteroskedastis pada regresi. Model regresi linier dapat disebut sebagai model yang baik jika model tersebut memenuhi beberapa asumsi klasik, yaitu data residual terdistribusi normal, tidak adanya multikolinieritas dan heterokedastisitas. Harus terpenuhinya asumsi klasik karena agar diperoleh model regresi dengan estimasi yang tidak bias dan pengujian dapat dipercaya. Tujuan utama dalam analisa regresi menduga fungsi regresi populasi berdasarkan fungsi regresi sampel setepat mungkin. Persamaan regresi digunakan untuk mengukur sikap siswa terhadap penerimaan teknologi[10].

\section{HASIL DAN PEMBAHASAN}

\subsection{Uji Validitas}

Validitas adalah suatu derajat ketepatan/ kelayakan instrumen yang digunakan untuk mengukur apa yang akan diukur (Zainal Ariffin, 2012). Sukardi (2013) menyatakan: validitas adalah derajat yang menunjukkan dimana suatu tes mengukur apa yang hendak diukur, sedangkan Saifuddin Azwar (2014) berpendapat bahwa validitas mengacu sejauh mana akurasi suatu tes atau skala dalam menjalankan fungsi pengukurannya.

Analisis faktor dilakukan dengan cara mengkorelasikan jumlah skor faktor dengan skor total. Bila korelasi tiap faktor tersebut positif dan besarnya 0,3 ke atas maka faktor tersebut merupakan construct yang kuat [10].

Hasil uji validitas dari ketiga variabel dalam penelitian ini dapat dillihat pada tabel berikut:

Tabel 1 Hasil Uji Validitas

\begin{tabular}{|c|c|c|c|}
\hline No & R Hitung & r Tabel & Keputusan \\
\hline \multicolumn{3}{|c|}{ Kemudahan Pengguna (X1) } \\
\hline 1 & 0,500 & 0,30 & Valid \\
\hline 2 & 0,668 & 0,30 & Valid \\
\hline 3 & 0,602 & 0,30 & Valid \\
\hline 4 & 0,447 & 0,30 & Valid \\
\hline 5 & 0,566 & 0,30 & Valid \\
\hline \multicolumn{4}{|c|}{ Materi Aplikasi (X2) } \\
\hline 1 & 0,649 & 0,30 & Valid \\
\hline 2 & 0,681 & 0,30 & Valid \\
\hline 3 & 0,620 & 0,30 & Valid \\
\hline 4 & 0,612 & 0,30 & Valid \\
\hline 5 & 0,458 & 0,30 & Valid \\
\hline Manfaat Aplikasi (X3) \\
\hline 1 & 0,596 & 0,30 & Valid \\
\hline 2 & 0,645 & 0,30 & Valid \\
\hline 3 & 0,565 & 0,30 & Valid \\
\hline 4 & 0,666 & 0,30 & Valid \\
\hline 5 & 0,517 & 0,30 & Valid \\
\hline Pengaruh Aplikasi \\
\hline 1 & 0,618 & 0,30 & Valid \\
\hline 2 & 0,708 & 0,30 & Valid \\
\hline 3 & 0,635 & 0,30 & Valid \\
\hline
\end{tabular}

Berdasarkan hasil uji coba instrumen penelitian pada tabel pengujian validitas terlihat bahwa rHitung lebih besar dari rTabel yang artinya seluruh item angket tersebut dinyatakan valid dan bisa dijadikan sebagai alat pengumpulan data dalam penelitian yang dilakukan. 


\subsection{Uji Reliabilitas}

Uji reliabilitas dilakukan untuk menguji tingkat ketepatan instrumen akurat atau tidak. Dari data kuesioner yang diperoleh maka dapat dicapai reliabilitasnya dengan menggunakan rumus Cronbach's Alpha. [10].

Pada uji reliabilitas, didapat dengan menggunakan uji Cronbach's ALPHA. Hasil yang didapat adalah seluruh item-item dalam penelitian ini memiliki nilai Cronbach's ALPHA yang lebih besar dari 0,6 sehingga seluruh indikator/item dinyatakan reliabel[11]. Berikut adalah hasil reliabilitas dalam penelitian ini:

\section{Tabel 2 Hasil Uji Reliabilitas}

\begin{tabular}{|c|c|c|}
\hline r Hitung & r Tabel & Keputusan \\
\hline 0,757 & 0,60 & Valid \\
\hline
\end{tabular}

Berdasarkan hasil pengujian reliablitas sebesar 0,757 > 0,60, maka dapat dikatakan bahwa angket tersebut dinyatakan reliabel dan angket dapat digunakan untuk penelitian

\subsection{Uji Asumsi Klasik}

\subsubsection{Normalitas Resedual}

Uji normalitas data digunakan untuk mengetahui apakah yang diperoleh berdistribusi normal atau tidak [10]. Berikut adalah hasil uji normalitas:

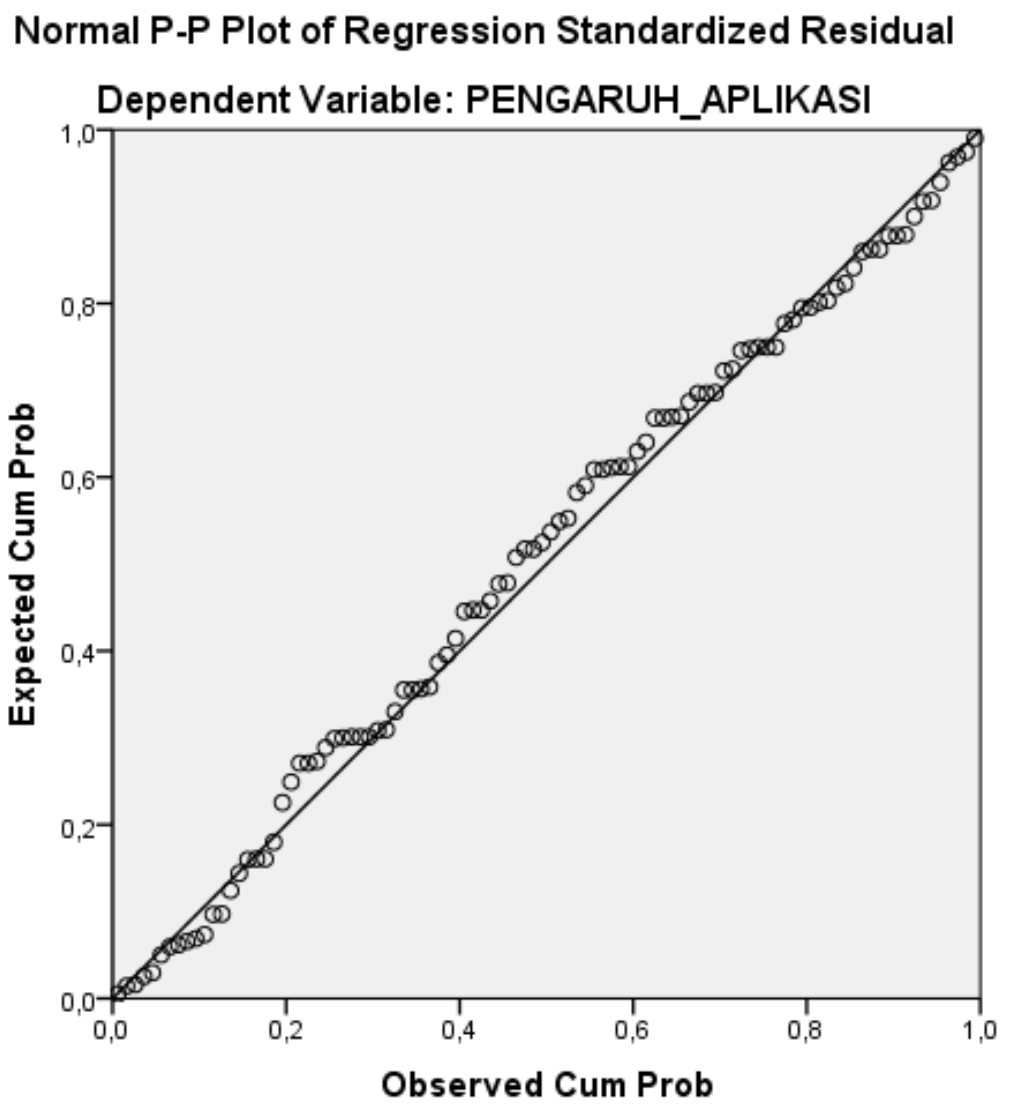

\section{Gambar 1 Grafik hasil uji normalitas}

Dari diatas diketahui bahwa titik-titik menyebar sekitar garis dan mengikuti garis diagonal, maka nilai residual tersebut berdistribusi normal.

Tabel 3 Hasil Uji Reliabilitas

\section{One-Sample Kolmogorov-Smirnov Test}




\begin{tabular}{llr}
\hline $\mathrm{N}$ & & 100 \\
\hline Normal & Mean &, 0000000 \\
\cline { 2 - 3 } Parameters & Std. &, 94801051 \\
& Deviation &, 060 \\
\hline \multirow{2}{*}{$\begin{array}{l}\text { Most Extreme } \\
\text { Differences }\end{array}$} & Absolute &, 040 \\
\cline { 2 - 3 } & Positive &,- 060 \\
\cline { 2 - 3 } & Negative &, 060 \\
\hline Test Statistic & &, $200^{\mathrm{c}, \mathrm{d}}$ \\
\hline Asymp. Sig. (2-tailed)
\end{tabular}

a. Test distribution is Normal.

b. Calculated from data.

Dari output di atas dapat terlihat bahwa nilai signifikansi (Asmp.Sig 2-tailed) sebesar 0,200 c.d Karena nilai signifikansi lebih besar dari 0,05, maka nilai residual terdistribusi dengan normal.

\subsubsection{Uji Multikolinieritas}

Pengujian ini dilakukan untuk mengetahui apakah ada atau tidaknya multikolinieritas. Karena model regresi yang baik seharusnya tidak adanya multikolinieritas [10].

Tabel 4 Hasil uji multikolinieritas

\begin{tabular}{|c|c|c|c|c|c|c|c|c|}
\hline \multicolumn{9}{|c|}{ Coefficients $^{\mathbf{a}}$} \\
\hline & & \multicolumn{2}{|c|}{$\begin{array}{l}\text { Unstandardized } \\
\text { Coefficients }\end{array}$} & \multirow{2}{*}{$\begin{array}{c}\begin{array}{c}\text { Standardized } \\
\text { Coefficients }\end{array} \\
\text { Beta }\end{array}$} & \multirow[b]{2}{*}{$\mathrm{T}$} & \multirow[b]{2}{*}{ Sig. } & \multicolumn{2}{|c|}{$\begin{array}{l}\text { Collinearity } \\
\text { Statistics }\end{array}$} \\
\hline \multicolumn{2}{|c|}{ Model } & B & $\begin{array}{l}\text { Std. } \\
\text { Error }\end{array}$ & & & & Tolerance & VIF \\
\hline \multirow[t]{4}{*}{1} & (Constant) & 5,133 & 1,571 & & 3,268 & ,002 & & \\
\hline & $\mathrm{X} 1$ &, 227 &, 084 &, 313 & 2,690 &, 008 &, 575 & 1,740 \\
\hline & $\mathrm{X} 2$ &,- 003 &, 061 &,- 005 &,- 048 & ,962 &, 745 & 1,343 \\
\hline & X3 &, 150 &, 072 &, 245 & 2,070 &, 041 & ,558 & 1,793 \\
\hline
\end{tabular}

Dari tabel di atas terlihat bahwa nilai Torelance ketiga variabel bernilai $0,575(\mathrm{X} 1), 0,745(\mathrm{X} 2)$, $0,558(\mathrm{X} 3)$ yang artinya lebih dari 0,10 dan nilai VIF dari ketiga variabel 1,740(X1), 1,343(X2), 1,793(X3) yang artinya kurang dari 10, maka dapat disimpulkan bahwa tidak terjadi multikolinieritas antar variabel bebas.

\subsubsection{Uji Heteroskedastisitas}

Pengujian ini dilakukan untuk mengetahui apakah ada atau tidaknya heterokedastisitas. Karena model regresi yang baik seharusnya tidak adanya heterokedastisitas [10]. 


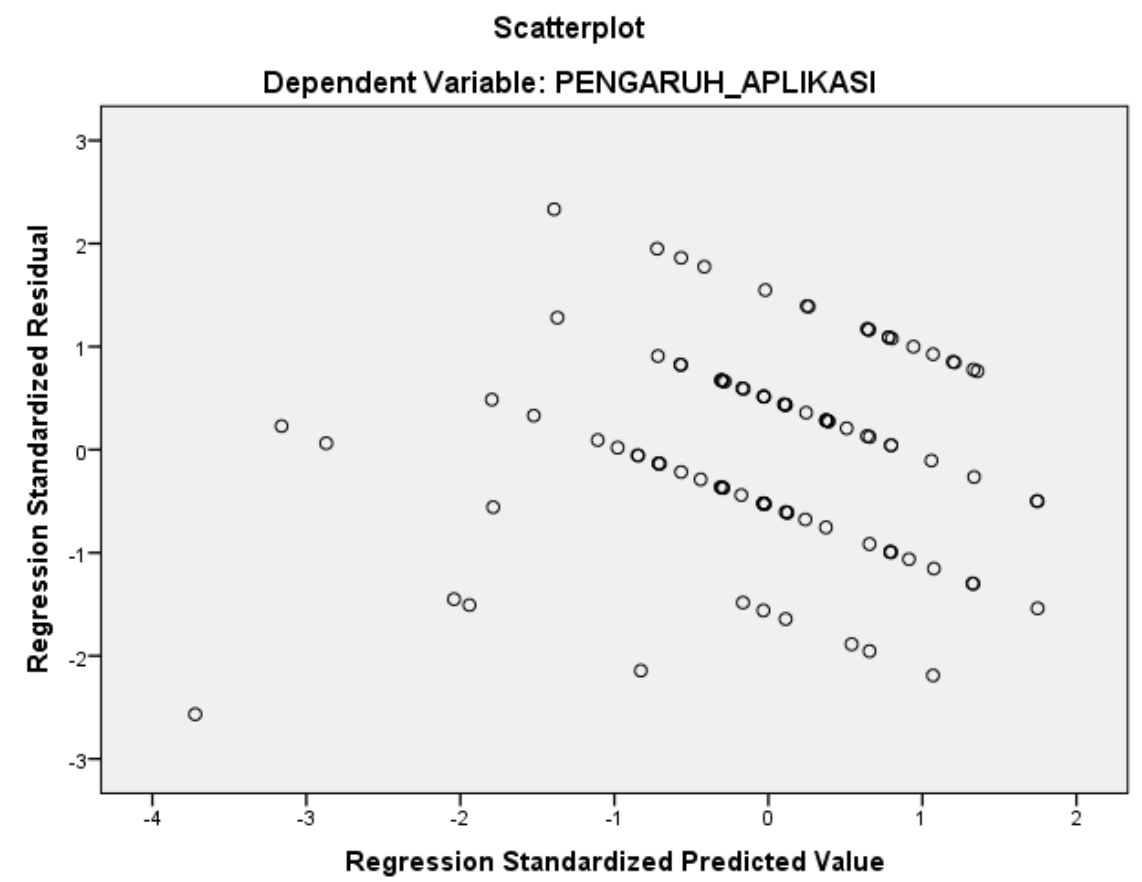

Gambar 2 Grafik hasil uji heteroskedastisitas

Dari Gambar 2 dapat diketahui bahwa titik-titik tidak membentuk pola yang tidak jelas, dan titik-titik menyebar diatas dan dibawah angka 0 pada sumbu Y. Jadi dapat disimpulkan bahwa tidak terjadi masalah heteroskedastisitas pada model regresi.

Tabel 5 Tabel hasil uji heteroskedastisitas

\begin{tabular}{|c|c|c|c|c|c|c|}
\hline \multicolumn{7}{|c|}{ Coefficients $^{\mathrm{a}}$} \\
\hline & & \multicolumn{2}{|c|}{$\begin{array}{l}\text { Unstandardized } \\
\text { Coefficients }\end{array}$} & \multirow{2}{*}{$\begin{array}{l}\text { Standardized } \\
\text { Coefficients }\end{array}$} & & \\
\hline \multicolumn{2}{|c|}{ Model } & B & Std.Error & & $\mathrm{T}$ & Sig. \\
\hline \multirow{4}{*}{1} & (Constant) & 1,217 & ,928 & & 1,311 & , 193 \\
\hline & $\mathrm{X} 1$ &, 026 & 050 & ,071 & .530 & .597 \\
\hline & $\mathrm{X} 2$ &,- 036 & 036 &,- 119 & $-1,011$ & 315 \\
\hline & $\mathrm{X} 3$ &,- 012 & ,043 &,- 037 &,- 269 &, 788 \\
\hline
\end{tabular}

Dari tabel dapat diketahui bahwa nilai signifikansi X1 sebesar 0,597 signifikansi X2 sebesar 0,315 dan signifikansi X3 sebesar 0,788 . Dengan demikian nilai dari ketiga variabel indipenden lebih dari 0,05 dan dapat disimpulkan bahwa tidak terjadi masalah heteroskedastisitas pada model regresi.

\subsection{Analisa Regresi Linier Berganda}

Berdasarkan hasil uji asumsi klasik yang dilakukan dan hasilnya menunjukkan bahwa normalitas residual berdistribusi normal, tidak adanya multikolinieritas, dan heteroskedastis. Maka langkah selanjutnya melakukan analisis Regresi Linier Berganda. Tingkat signifikansi yang digunakan adalah sebesar alpha $5 \%$ atau sebesar 0,05 . 


\subsubsection{Koefisien Determinasi}

Tabel 6 Hasil Uji Determinasi

\begin{tabular}{|c|c|c|c|c|}
\hline \multicolumn{5}{|c|}{ Model Summary } \\
\hline Model & $\mathrm{R}$ & $\begin{array}{c}\mathrm{R} \\
\text { Square }\end{array}$ & $\begin{array}{c}\text { Adjusted } \\
\text { R Square }\end{array}$ & $\begin{array}{c}\text { Std. } \\
\text { Error of } \\
\text { the } \\
\text { Estimate }\end{array}$ \\
\hline 1 &, $502^{\mathrm{a}}$ &, 252 &, 229 &, 963 \\
\hline \multicolumn{2}{|l|}{ a. Predictors: (Constant), X1, X2, X3 } \\
\hline \multicolumn{2}{|l}{ b. Dependent Variable : Pemahaman } \\
\hline
\end{tabular}

Dari hasil uji koefesien determinasi, terlihat nilai koefisien determinasi R Square menunjukkan nilai sebesar 0,252 artinya persentase variabel independent kemudahan pengguna (X1), materi aplikasi (X2) dan manfaat aplikasi (X3) berpengaruh terhadap pengaruh aplikasi (Y) sebesar 25,2\%, sedangkan sisanya 74,8\% dipengaruhi oleh variabel lain diluar dari penelitian ini.

\subsubsection{Uji Stimultan (Uji F)}

Uji $\mathrm{F}$ digunakan untuk mengetahui apakah variabel kemudahan penggunaan (X1) isi materi aplikasi (X2) dan manfaat aplikasi (X3) disebut independent secara simultan (bersama-sama) berpengaruh signifikan terhadap variabel pemahaman pelajaran $(\mathrm{Y})$ atau dependent.

Merumuskan Hipotesis:

Ho = variabel independent atau kemudahan (X1) isi materi (X2) dan kemanfaatan (X3) secara simultan (bersama-sama) tidak berpengaruh signifikansi terhadap variabel dependent atau sikap (Y).

$\mathrm{Ha}=$ variabel independent atau kemudahan (X1) isi materi (X2) dan kemanfaatan (X3) secara simultan (bersama-sama) berpengaruh signifikansi terhadap variabel dependent atau sikap (Y).

Tabel 7 Hasil Uji Stimultan (Uji F)

\begin{tabular}{|c|c|c|c|c|c|c|}
\hline \multicolumn{7}{|c|}{ ANOVA $^{a}$} \\
\hline \multicolumn{2}{|c|}{ Model } & $\begin{array}{l}\text { Sum of } \\
\text { Squares }\end{array}$ & df & $\begin{array}{l}\text { Mean } \\
\text { Square }\end{array}$ & $\mathrm{F}$ & Sig. \\
\hline \multirow[t]{3}{*}{1} & Regression & 29,986 & 3 & 9,995 & 10,785 &, $000^{\mathrm{b}}$ \\
\hline & Residual & 88,974 & 96 &, 927 & & \\
\hline & Total & 118,960 & 99 & & & \\
\hline \multicolumn{7}{|c|}{ a. Dependent Variable: PEMAHAMAN } \\
\hline \multicolumn{7}{|c|}{$\begin{array}{l}\text { b.Predictors: } \quad \text { (Constant), } \quad \text { Manfaat_Aplikasi, } \\
\text { Materi_Aplikasi, Kemudahan_Pengguna }\end{array}$} \\
\hline
\end{tabular}

Dari hasil uji simultan (Uji F) diperoleh nilai $F$ hitung sebesar 10,785 dengan nilai signifikansi uji F 0,000. Karena nilai signifikansi lebih kecil dari 0,05 maka dapat disimpulkan Ha diterima yaitu variabel kemudahan pengguna (X1), variabel isi materi aplikasi (X2) dan manfaat aplikasi (X3) atau independent secara simultan (bersama-sama) berpengaruh signifikansi terhadap variabel pengaruh aplikasi (Y) atau dependent

\subsubsection{Uji Parsial (Uji t)}

Uji t digunakan untuk mengetahui apakah variabel kemudahan penggunaan (X1) isi materi aplikasi (X2) dan manfaat aplikasi (X3) disebut independent secara parsial berpengaruh nyata atau tidak terhadap pemahaman pelajaran $(\mathrm{Y})$ atau dependent. Pengujian ini menggunakan tingkat signifikansi 0,05 .

Merumuskan Hipotesis:

$\mathrm{Ho}=$ variabel independent secara parsial tidak berpengaruh signifikansi terhadap variabel dependent .

Haerul Fatah, Analisis Pengaruh Aplikasi Pembelajaran Aksara Sunda Terhadap Pemahaman Siswa Dengan Metode TAM 
$\mathrm{Ha}=$ variabel independent secara parsial berpengaruh signifikansi terhadap variabel dependent .

Mencari t tabel:

$\mathrm{T}$ tabel $=(\alpha / 2 ; \mathrm{n}-\mathrm{k}-1)$

$\mathrm{T}$ tabel $=(0,05 / 2 ; 100-3-1)$

T tabel $=(0,025 ; 96)$

Ditemukan pada distribusi nilai t tabel adalah 1, 988.

Tabel 8 Hasil Uji Parsial (Uji t)

\begin{tabular}{|c|c|c|c|c|c|c|}
\hline \multicolumn{7}{|c|}{ Coefficients $^{\mathbf{a}}$} \\
\hline & & \multicolumn{2}{|c|}{$\begin{array}{l}\text { Unstandardized } \\
\text { Coefficients }\end{array}$} & \multirow{2}{*}{$\begin{array}{l}\text { Standardized } \\
\text { Coefficients } \\
\text { Beta }\end{array}$} & & \\
\hline \multicolumn{2}{|c|}{ Model } & B & Std.Error & & $\mathrm{T}$ & Sig. \\
\hline \multirow{4}{*}{1} & (Constant) & 5,133 & 1,571 & & 3,268 & ,002 \\
\hline & $\mathrm{X} 1$ &, 227 &, 084 & ,313 & 2,690 &, 008 \\
\hline & $\mathrm{X} 2$ &,- 003 & ,061 &,- 005 &,- 048 & ,962 \\
\hline & $\mathrm{X} 3$ &,- 150 & ,072 &,- 245 & 2,070 & 041 \\
\hline
\end{tabular}

Dari hasil uji prtisial (Uji t) nilai t hitung variabel kemudahan (X1) 2,690 > 1,988 dan nilai signifikansi $(0,008<0,05)$, maka dapat disimpulkan bahwa Ho ditolak dan Ha diterima, yang berarti variabel kemudahan penggunaan berpengaruh signifikan terhadap pemahaman pelajaran.

Nilai thitung variabel isi materi aplikasi (X2) -0,048 < 1,988 dan nilai signifikansi $(0,962>0,05)$, maka dapat disimpulkan bahwa Ho diterima dan Ha ditolak, yang berarti variabel isi materi aplikasi tidak berpengaruh signifikan terhadap pemahaman pelajaran.

Nilai t hitung variabel manfaat (X3) 2,070 > 1,988 dan nilai signifikansi $(0,041<0,05)$, maka dapat disimpulkan bahwa Ho ditolak dan Ha diterima, yang berarti variabel manfaat berpengaruh signifikan terhadap pemahaman pelajaran.

Berdasarkan hasil analisis regresi linier berganda menunjukkan bahwa besarnya nilai constant yang dihasilkan 5,133 dan koefisien regresi untuk variabel kemudahan X1 sebesar 0,313 dan nilainya positif, variabel isi materi X2 sebesar -0,005 dan nilainya negatif sedangkan variabel manfaat X3 sebesar 0,245 dan nilainya negatif.

Dengan demikian dapat diperoleh persamaan regresi sebagai berikut:

$Y=5,133+0,313 \times 1-0,005 \times 2-0,245 \times 3$.

\section{KESIMPULAN}

Berdasarkan hasil penelitian yang dilakukan dapat diambil kesimpulan bahwa dari pengambilan sampel sebanyak 100 responden di SMAN 1 Singaparna, dapat diketahui bahwa 25,2\% siswa/i menerima dengan adanya aplikasi pembelajaran aksara sunda berbasis android berdasarkan dari kemudahan, isi materi dan kemanfaatan aplikasi. Hasil dari ketiga hipotesis yang diuji, menghasilkan bahwa hanya $\mathrm{H} 1$ dan $\mathrm{H} 3$ saja yang dapat diterima, yaitu Kemudahan penggunaan dan manfaat aplikasi berpengaruh terhadap pemahaman pelajaran aksara sunda. Hal ini disebabkan karena Nilai t hitung variabel isi materi aplikasi lebih kecil dari $5 \%(-0,048<1,988)$ dan nilai signifikansi lebih besar dari $5 \%(0,962>0,05)$, maka dapat disimpulkan bahwa $\mathrm{H} 2$ ditolak.

Terdapat pengaruh yang signifikan antara kemudahan penggunaan dan manfaat aplikasi terhadap pemahaman pelajaran aksara sunda. Semakin mudah penggunaan aplikasi dan semakin banyak manfaat dari aplikasi maka semakin tinggi pula pemahaman siswa-siswi dalam menerima pelajaran aksara sunda. 


\section{REFERENSI}

[1] J. Sundari, "Melestarikan Aksara Sunda Dengan Aplikasi Multimedia," J. Evolusi, vol. 4, no. 2, p. 28, 2016, doi: 10.5151/cidi2017-060.

[2] S. M. Holida, T. Alawiyah, and H. Sutisna, "Penerapan Animasi Interaktif Dalam Pengenalan Aksara Sunda," J. Inform., vol. 1, no. 2, pp. 111-122, 2016, doi: 10.31311/ji.v1i2.39.

[3] M. Shobary, D. Riana, and R. Sanjaya, "Pencampuran Tiga Warna Primer Dan Pengenalan Bentuk Geometri Pada Paud Al-Muslimun,” J. Inform., vol. I, no. 2, pp. 165-173, 2014.

[4] M. F. Adiwisastra, "Perancangan Game Kuis Interaktif Sebagai Multimedia Pembelajaran Drill and Practice Untuk Meningkatkan Hasil Belajar Siswa," J. Inform., vol. 2, no. 1, pp. 205-211, 2016, doi: 10.31311/ji.v2i1.67.

[5] W. H. Suhartini, Dwi, "MODEL PENERIMAAN TEKNOLOGI INFORMASI OLEH DOSEN PADA PERGURUAN TINGGI DI SURABAYA," in SEMINAR NASIONAL IMPLEMENTASI SISTEM MANAJEMEN KUALITAS ISO 9001-2008 DAN IWA 2 DALAM UPAYA MENINGKATKAN KUALITAS DOSEN DAN MAHASISWA FAKULTAS EKNOMI UPN "VETERAN" JAWA TIMUR, 2009, vol. 45, no. 1, pp. 1-19, doi: 10.7202/1016404ar.

[6] D. Yuniarto, "Analisis Penerimaan Penggunaan Aplikasi Laporan Beban Kerja Dosen Dan Evaluasi Pelaksanaan Tridharma Perguruan Tinggi Secara Online Menggunakan Technology Acceptance Model (TAM) (Studi Kasus Di Lingkungan Perguruan Tinggi Sebelas April Dan STMIK Sumedang)," Infoman's, vol. 12, no. 1, pp. 26-35, 2018, doi: 10.33481/infomans.v12i1.48.

[7] F. Budiman and F. I. Arza, "Pendekatan Technology Acceptance Model Dalam Kesuksesan Implementasi Sistem Informasi Manajamen Daerah,” Wahana Ris. Akunt., vol. 1, no. 1, pp. 87110, 2013.

[8] D. Hillery, R. D. T. Ediraras, and P. R. Wulansari, "Penerapan Teknologi Informasi dan Komunikasi (TIK) Pada UMKM Menggunakan Technology Acceptance Model (TAM) (Studi Kasus di Depok dan Qingdao)," Lemb. Penelit. Univ. Gunadarma, vol. Vol. 7, pp. 94-100, 2012.

[9] A. Muhammad, "Analisis Penerimaan Komputer Mikro Dengan Menggunakan Technology Acceptance Model (Tam) Pada Kantor Akuntan Publik (Kap) Di Jawa Tengah Skripsi," J. STIE SEmarang, vol. 3, no. 2, pp. 47-73, 2010.

[10] F. Febriyanti and K. Widianto, "Pengukuran Penggunaan E-Learning Pada Smk - Smak Bogor," Jurnalilmu Pengetah. Dan Teknol. Komput. Pengukuran, vol. 2, no. 2, pp. 32-38, 2017.

[11] Imandari, Fitri, Endang Siti Astuti, Muhammad Saifi, "Pengaruh Persepsi Kemanfaatan dan Persepsi Kemudahan Terhadap Minat Berprilaku Dalam Penggunaan E-Learning, Jurnal Administrasi Bisnis, ”J.Administrasi Bisnis, vol. 3, no. 4, 2013

[12] Pribadi, Ganteng Eki, Undang Syaripudin dan Wisnu Uriawan. “Aplikasi Pembelajaran Bahasa Sunda dengan Implementasi Algoritma Linear Congruental Generator dan Fuzzy Berbassi Android," JOIN. Vol.I No.1 Juni 2016: 34-42

[13] Sayekti, Fran \& Pulasna Putarta, "Penerapan Technology Acceptance Model (Tam) Dalam Pengujian Model Penerimaan Sistem Informasi Keuangan Daerah, " J. Manajemen Teori dan Terapan Tahun 9. No. 3, 2016

[14] Hanggono , Aditya Arie, Siti Ragil Handayani, Heru Susilo. "Analisis Atas Praktek Tam (Technology Acceptance Model) Dalam Mendukung Bisnis Online Dengan Memanfaatkan Jejaring Sosial Instagram," J.Administrasi Bisnis (JAB). Vol. 26 No. 1, 2015

[15] Tasmil \& Herman. (2015). "Penerapan Model TAM untuk Menilai Tingkat Penerimaan Nelayan terhadap Penggunaan GPS, ” J.Pekommas, Vol. 18 No. 3, Desember 2015: 161 - 170 